\title{
Exploiting Fine-Scale Data in Modeling Migrants' Settlement Patterns in Europe
}

\section{Angelo Mazza ${ }^{1}$}

Accepted: 29 November 2020 / Published online: 16 December 2020

(C) The Author(s), under exclusive licence to Springer Nature Switzerland AG part of Springer Nature 2020

Residential location influences proximity to critical resources, such as schools, hospitals, childcare facilities, and employment opportunities, but also to environmental and social hazards, such as exposure to crime and violence (Reardon 2006). Moreover, it affects access to social networks, other forms of social capital, and it shapes human interaction and the demographic processes that originate from it, like mortality, fertility, and mobility (Almquist and Butts 2012). Hence, residential segregation of demographic groups, often related to ethnicity or social status, leading to the creation of enclaves or ghettos is a significant topic of interest among social scientists (Massey and Denton 1988; Singh et al. 2009). This topic is of increased relevance among European scholars following recent debates that link segregation with the perceived failure of integrating immigrants into host societies (Kalandides and Vaiou 2012; Andersson 2013). The 'war on terror' and the threats to the economy, culture, and 'national security' posed by immigrants and their descendants, has heightened anxieties about their inclusion within host societies (Phillips 2010), and especially in regions where the contribution of migration to the change in population size or composition is significant.

In broad terms, a minority group is segregated when its households' spatial arrangement departs from expectations based upon a random spatial allocation (Freeman et al. 1971). Traditional segregation studies rely on data aggregated by areal units, typically census tracts. However, this approach has several drawbacks. First, there is the "modifiable area unit problem," i.e., alternative zoning or different scales might yield different results (Openshaw 1984). Furthermore, census tracts may change in size and shape, and different countries might use different zoning systems; these issues can make comparisons over time and space inconsistent. The five papers in this Special Issue, all leveraging fine-scale data, explore substantive and methodological issues in a set of empirical studies from Europe.

Angelo Mazza

a.mazza@unict.it

1 Department of Economics and Business, University of Catania, Corso Italia, 55, 95129 Catania, Italy 
In the first paper of this Special Issue, Catney and Lloyd pinpoint that tract-level analysis limitations are particularly significant when dealing with ethnic and racial studies, where spatial pattern alterations are likely to be highly localized. They provide a comprehensive illustration of population data grids' potential as an effective means for studying long-term fine-scale changes in ethnic diversity and segregation. Catney and Lloyd take advantage of a new and open data source, PopChange (https://www.qub.ac.uk/research-centres/GIS/Research/PopChange/), that provides a $1 \mathrm{~km}$ by $1 \mathrm{~km}$ gridded data on country of birth (1971-2011) and ethnic group (1991-2011) for the whole of Great Britain. Their analysis provides insights on forty years of change in ethnic diversity and segregation across Britain. As residential segregation has steadily declined, trends in ethnic diversity show an increase, with the all-time higher levels of diversity of urban areas "spreading out" in suburban and rural areas. The authors summarise the spatial extent of diversity using variograms estimated from the reciprocal diversity index. A graph with variograms over five time-points is an original and effective way to evaluate how the extent of diversity has changed over a long period. The authors measured micro-scale changes in residential segregation using the dissimilarity index (Duncan and Duncan 1955). Although many segregation indexes have been suggested, with different formulations referring to different definitions of segregation (for an overview, see Massey and Denton 1988), the dissimilarity index is still the most widely used. Piekut et al. (2019) report that in 2018 a Google Scholar search for the 'index of dissimilarity' revealed 176,000 scholarly articles, 24,000 of which have been published since 2014; at the end of 2020, the same search reports 218,000 articles. $^{1}$ Indeed, three of the five contributions in this Special Issue measure segregation with it.

Olteanu et al. outline an intriguing new methodology, the distortion analysis, that measures the extent to which some specified small area and the continuous sequence of bespoke neighborhoods around it are similar to, or different from, the citywide average. Distortion analysis allows for the measuring of segregation at multiple scales, taking full advantage of fine resolution data. Furthermore, whereas the dissimilarity index's sensitivity to random allocation implies an upward bias, their approach is much less sensitive to sampling effects. The authors illustrate their technique through a case study related to Chinese and Algerian citizens in Paris. Olteanu et al. and three other contributors of this Special Issue exploit the D4I dataset (Data for Integration dataset, https://ec.europa.eu/knowledge4policy/migration-demog raphy/data-integration-d4i_en), recently released by the European Commission's Knowledge Centre on Migration and Demography. This dataset was produced from harmonizing official census statistics collected by National Statistical Institutes in eight E.U. Member States. The dataset provides gridded data (cells of $100 \mathrm{~m}$ by $100 \mathrm{~m}$ ) of the population with migrant backgrounds; see Alessandrini et al. (2017) for a detailed description.

The D4I dataset provides consistent data for France, Germany, Ireland, Italy, Netherlands, Portugal, Spain, and the U.K. Benassi et al. take full advantage of the D4I data coverage to make comparisons of spatial segregation in all Functional

\footnotetext{
${ }^{1}$ Note that both Google Scholar queries were carried out without quoting the search string.
} 
Urban Areas of the eight European countries covered by D4I. They analyze demographic and economic factors that influence segregation, showing that whereas larger metropolitan areas attract more migrants, the highest residential segregation levels are in smaller urban areas. Moreover, key national peculiarities emerge, with countries of North-Western Europe recording lower levels of residential segregation compared to those patterns found within the Southern European countries.

Kalantaryan and Alessandrini consider the influence of immigration on the wellbeing of Italian natives through its effects on the dynamics of the real estate market, a central issue in the current debate on the consequences of migration in Europe. They integrate the DI4 dataset with data on house prices and rents that the Italian Revenue Agency periodically releases for homogenous micro-areas. Their findings suggest that natives see immigrants' presence as an adverse amenity, with more diverse neighborhoods exhibiting lower housing values. Furthermore, the extra demand created by the inflow of migrants seems to increase house values, but only up to a critical immigrant concentration, after which natives begin to leave for other residential areas, causing a decrease in house values.

In the final paper of this Special Issue, Lopez Gay et al. focus on how migration and residential mobility change Barcelona and Madrid's social composition at a neighborhood scale. They take advantage of a register-based dataset accounting for flows into, out of, and within Barcelona and Madrid's municipalities between 2011 and 2017. Notably, data available include the educational attainment of every individual moving; this dataset, unique for Spain, allowed the authors a thorough characterization of the interconnected processes of population substitution, polarization, and segregation. Immigration, which has been declining after the 2008 economic crisis, since 2014 is experiencing a remarkable increase, characterized by a share of the highly educated migrants higher than ever, especially from abroad. These changes in the composition of migration inflows initiated, in both cities, a social restructuration process that boosted transformations in the social hierarchy of the urban space.

When accessible, as in Lopez Gay et al., individual-level information is ideal; the availability of individual household locations would allow the use of distance-based indicators, avoiding spatial aggregation altogether. ${ }^{2}$ However, individual household locations are usually not offered for privacy or administrative costs. ${ }^{3}$ Catney and Lloyd made a point that population grids can provide an effective means for multiscale, long-term, and inter-country studies; Benassi et al. provided an example of exploiting both the fine-scale and the broad geographical coverage of the D4I dataset to achieve consistent comparisons across diverse countries.

Although its sensitivity to random allocation implies an upward bias, especially when dealing with smaller spatial units, smaller minority proportions, and lower segregation levels, ${ }^{4}$ the dissimilarity index is still the most common measure of segregation.

\footnotetext{
2 An example of segregation study that use individual household data is Mazza and Punzo (2016).

${ }^{3}$ Almquist and Butts (2012) provide a method to effectively simulate the location of individual households within small areal units.

${ }^{4}$ Mazza and Punzo (2015) give analytical proof of the non-negativity of the bias of the dissimilarity index and provide a bias correction procedure based on resampling.
} 
All in all, the increasing availability of fine-scale data, consistent over time and space, suggests that it might be the time to move beyond census tract data (Lee et al. 2008). Moreover, the distortion analysis introduced by Olteanu et al. provides one option for also leaving the dissimilarity index behind.

I would like to thank Stephen A. Matthews, Editor-in-Chief of Spatial Demography, for allowing me to edit this Special Issue, the authors who contributed to this volume, and all the reviewers.

\section{References}

Alessandrini, A., Natale, F., Sermi, F., \& Vespe, M. (2017). High resolution map of migrants in the E.U. JRC Technical Reports, 199.

Almquist, Z. W., \& Butts, C. T. (2012). Point process models for household distributions within small areal units. Demographic Research, S13(22), 593-632.

Andersson, R. (2013). Reproducing and reshaping ethnic residential segregation in Stockholm: The role of selective migration moves. Geografiska Annaler: Series B, Human Geography, 95(2), 163-187.

Duncan, O., \& Duncan, B. (1955). A methodological analysis of segregation indexes. American Sociological Review, 41, 210-217.

Freeman, L., Pilger, J., \& Alexander, W. (1971). A measure of segregation based upon spatial arrangements. USA: University of Hawaii.

Kalandides, A., \& Vaiou, D. (2012). 'Ethnic' neighborhoods? Practices of belonging and claims to the city. European Urban and Regional Studies, 19(3), 254-266.

Lee, B. A., Reardon, S. F., Firebaugh, G., Farrell, C. R., Matthews, S. A., \& O’Sullivan, D. (2008). Beyond the census tract: Patterns and determinants of racial segregation at multiple geographic scales. American Sociological Review, 73(5), 766-791.

Massey, D., \& Denton, N. (1988). The dimensions of residential segregation. Socia Forces, 67(2), 281-315.

Mazza, A., \& Punzo, A. (2015). On the upward bias of the dissimilarity index and its corrections. Sociological Methods \& Research, 44(1), 80-107.

Mazza, A., \& Punzo, A. (2016). Spatial attraction in migrants' settlement patterns in the city of Catania. Demographic Research, 35, 117-138.

Openshaw, S. (1984). The modifiable areal unit problem. Norwich: Geobooks, University of East Anglia.

Phillips, D. (2010). Minority ethnic segregation, integration and citizenship: A European perspective. Journal of Ethnic and Migration Studies, 36(2), 209-225.

Piekut, A., Pryce, G., \& van Gent, W. (2019). Segregation in the twenty first century: Processes, complexities and future directions. Tijds. voor econ. en Soc. Geog., 110, 225-234.

Reardon, S. F. (2006). A conceptual framework for measuring segregation and its association with population outcomes. In J. Oakes \& J. Kaufman (Eds.), Methods in social epidemiology (pp. 169-192). San Francisco: Jossey-Bass.

Singh, A., Vainchtein, D., \& Weiss, H. (2009). Schelling's segregation model: Parameters, scaling, and aggregation. Demographic Research, 21(12), 341-366.

Publisher's Note Springer Nature remains neutral with regard to jurisdictional claims in published maps and institutional affiliations. 